\title{
ÖZLEM AYAZLI, ALTUN YARUK SUDUR VI. KITAP (Karşılaştırmalı Metin Yayını)
}

Türk Dil Kurumu Yayınları, Ankara 2012, 506 s.

Kenan AZILI*

"Namo buddaya namo darmaya namo sangaya..."

\section{Dr. Özlem Ayazlı'nın Öz Geçmişi ***}

Özlem Ayazlı, 1980 yılında Velbert - Almanya'da dünyaya gelir. 2002 y1lında Mersin Üniversitesi Fen Edebiyat Fakültesi Türk Dili ve Edebiyatı Bölümünden lisans mezunu olan Ayazlı, Yıldız Teknik Üniversitesinde yüksek lisans eğitimine başlar ve 2005 yılında mezun olur. Yine aynı üniversitede doktora eğitimine başlar. Bu aşamada bizim çalışmamızın esasını teşkil eden ve danışmanlığını Mehmet Ölmez'in yaptığı doktora tezini bilim dünyasına sunar. Ardından da doktora eğitimini 2009 yılında tamamlayarak "Doktor" unvanını alır. Şu an Cumhuriyet Üniversitesinde Yardımcı Doçent unvanı ile görev yapmaktadır. Yrd. Doç. Dr. Özlem Ayazlı'nın bugüne kadar yaptığı bütün çalışmaları şunlardır:

\section{$\underline{\text { Tezler }}$}

Garaib Hikâyeler. Mersin Üniversitesi Türk Dili ve Edebiyatı Bölümü (Mezuniyet Tezi), 2002.

Dindışı Eski Uygurca Metinlerin Karşılaştırmalı Sözvarlığı. Yıldız Teknik Üniversitesi, Sosyal Bilimler Enstitüsü (Yüksek Lisans Tezi), 2005.

Altun Yaruk Sudur, VI. Kitap. Yıldız Teknik Üniversitesi, Sosyal Bilimler Enstitüsü (Doktora Tezi), 2009.

\section{Uluslararası hakemli dergilerde yayınlanan makaleler}

CIVELEK, Ö. (2008). Eski Türkçe Çuvaşça Söz Denklikleri 1. Ünlüyle Başlayanlar, Journal of Turkish Studies, Türklük Bilgisi Araştırmaları. In Memoriam Sinasi Tekin III, Harvard University, 107-119.

\footnotetext{
*Arş. Gör.; Siirt Üniversitesi Edebiyat Fakültesi Türk Dili ve Edebiyatı Bölümü, kenanazili@ hotmail.com.

** Öz geçmiş yazarın kendisinden alınmıştır.
} 
AYAZLI, Ö. (2011). Mahayana Budizm'ine Ait Say1 ve Zamanla İlgili Bazı Terimler. Turkish Studies, International Periodical For The Languages, Literature and History of Turkish or Turkic, Volume 6/1 Winter, 635-641.

AYAZLI, Ö. (2012). Türk Düşünce Tarihinden Manzum Parçalar. Journal of Turkish Studies, Türklük Bilgisi Araştırmaları, C 38, 21-36.

\section{$\underline{\text { Uluslararası bilimsel toplantılarda sunulan ve bildiri kitabında basılan bildiriler }}$}

CiVELEK, Ö. (2008). Karakuş. Av ve Avcllı Kitabı, İstanbul. 89-101. ed. Emine Gürsoy Naskali - Hilal Oytun Altun.

AYAZLI, Ö. ve Ölmez M. (2011). Eski Uygurca Metinlerin Transkripsiyonunda Kullanılan Metinler ve İşaretler. Orta Asya'dan Anadolu'ya Alfabeler 29-30 Mayıs 2007, Eskişehir Bildiriler, İstanbul. 43-83.

\section{Uluslararası bilimsel toplantılarda özeti yavımlanmıs bildiriler}

CiVELEK, Ö. (2007). Din Dışı Eski Uygurca Metinlerdeki Bazı Tarım Terimleri Üzerine. 38. Uluslararası Asya ve Kuzey Afrika Çalışmaları Kongresi (ICANAS), Ankara. 188.

\section{Uluslararası bilimsel toplantılarda sunulmuș basılmamıș bildiriler}

AYAZLI, Ö. (2011). Singko Seli Tutung ve Altun Yaruk Çevirisi Üzerine. Uluslararası Eski Uygurca Araştırmaları Çalıştayı, 4-6 Haziran 2011, TDK, Ankara.

\section{$\underline{\text { Ulusal hakemli dergilerde yayımlanan makaleler }}$}

CIVELEK, Ö. (2006). Sözvarlığı Açısından Eski Türkçe ve Güney Sibirya Türk Dilleri. Sibirische Studien, Sibirya Incelemeleri, 69-104.

AYAZLI, Ö. (2008). Altun Yaruk’ta Geçen Sanskritçe Bazı Kelimelerin Çince Denklikleri. Türk Dilleri Araştırmaları, 18, 61-76.

AYAZLI, Ö. (2009). Sözvarlığı Açısından Anadolu Ağızları ve Sibir Grubu Türk Dilleri. Türk Dilleri Araştırmaları, 19, 33-46.

\section{Tanıtma, Eleștiri}

CIVELEK, Ö. (2004). Max Scherberger: Das Mir'acname Die Himmel und Höllenfahrt des Propheten Muhammed in der osttürkischen Überlieferung, Arbeitmaterialian zum Orient, Bd 14, Würzburg 2003, 153 s. Türk Dilleri Araştırmalar 14, İstanbul, 197-2001.

CIVELEK, Ö. (2005). A. Melek Özyetgin: Eski Türk Vergi Terimleri, Köksav yay., Ankara 2004, 250 s. Türk Dilleri Araştırmaları 15, İstanbul, 219-222. 
CIVELEK, Ö. (2005). Jacob M. Landau, Barbara Kellner-Heinkele: Politics of Language in the Ex-Soviet Muslum States, London 2001, 260 s. Türk Dilleri Araştırmaları 15, İstanbul, 235-237.

CIVELEK, Ö. (2007). Exploring the Eastern Frontiers of Turkic, Ed. Marcel Erdal and Irina Nevskaya, Turcologica 60, Wiesbaden 2006. Sibirische Studien, Sibirya incelemeleri, 2, 1. Göttingen- İstanbul, 103-110.

CIVELEK, Ö. (2007). Jens Wilkens, Die drei Körper des Buddha (trikaya), Ein Beitrag zum Verständnis einer zentralen Lehre des Mahayana-Budhismus, Berlin, 2001. Türk Dilleri Araştırmaları 17 İstanbul, 407-411.

AYAZLI, Ö. (2009). Divanü Lügati't-Türk'ün Kazakça Çevirisi, Temrin, Aylık Düşünce ve Edebiyat Dergisi, Kaşgarlı Mahmut Özel Sayısı, 10, 3132.

\section{$\underline{\text { Kitaplar }}$}

AYAZLI, Ö. (2012). Altun Yaruk Sudur VI, Karşılaştırmalı Metin Yayını. Ankara: Türk Dil Kurumu Yayınları.

AYAZLI, Ö. Dindışı Eski Uygur Metinleri. Türk Dil Kurumu (baskıda).

\section{Uygur Edebiyatı ve Altun Yaruk}

II. Köktürk Devleti'ni yıkarak daha sonra yönetime geçen Uygur Kağanlığı'nın Kırgızlarca yıkılması sonucu Uygurlar, Moğolistan'dan güneye veya güneybatıya göç etmişlerdir. Bugün bildiğimiz Şineiang Bölgesi'nde yerleşik hayata geçen Uygurlar, bu bölgede ağırlıklı olarak çeviri eserlerine dayanan bir edebiyat oluşturmuşlardır. Bu edebî ürünlerin neredeyse tamamına yakını dinî içerikli metinler olup birçoğu Budizm'e ait metinlerden oluşmaktadır (Ölmez, 2004: 129).

$\mathrm{Bu}$ çeviri metinlerin içerisindeki en mühim ve hacimli olanı ise Sanskritçesi Suvarnaprabhasa-sutra olan Altun Yaruk Sudurdur. Metnin Türkiye Türkçesi karş1lığ “Altın Işılk’tır. Uygur bilgini Beşbalıklı Şingko Şeli Tutung tarafından 10. yüzyılın ilk yarısında yazıldığı tahmin edilen Altun Yaruk'un Malov tarafindan bulunan nüshanın istinsahı 17. asırdadır (Ercilasun, 2004: 245). Ancak Berlin fragmanları bu tarihten daha eskiye dayanmaktadır. Özellikle Berlin fragmanlarındaki yazı çeşidi dikkate alındığında yirmiye yakın nüshası bulunan ve oldukça hacimli (Radloff ve Malov neşrinde 707 sayfa) olan Altun Yaruk, tamamen dinî 
öğretilerin bulunduğu sutraların ${ }^{1}$ en ehemmiyetlisi kabul edilmekte olup 10 kitap ve 31 bölümden oluşmaktadır.

Eser, 1910 yılında Rus Türkolog Sergev Malov tarafından Çin'in ufak bir köyündeki Budist tapınağında bulunmuştur. Altun Yaruk Sudur adlı eser öncelikle Çinceye daha sonra da Uygur Türkçesine çevrilmiştir. Altun Yaruk, Peter Zieme ve Jens Wilkens gibi önemli isimler tarafından çalışılmış olup Berlin Turfan Text serisinde çalışmaları yer almıştır. Bununla birlikte mezkûr eser; Saadet Çağatay, Şinasi Tekin, Reşid Rahmeti Arat, A. Von Gabain ve Wilhelm Radloff gibi önemli bilim adamlarınca da belirli parçalar hâlinde çalışılmıştır. Bunların dışında ülkemizde eser üzerine Mehmet Ölmez, Ceval Kaya ve Erdem Uçar gibi isimler doktora ve yüksek lisans tez çalışmaları yapmışlardır.

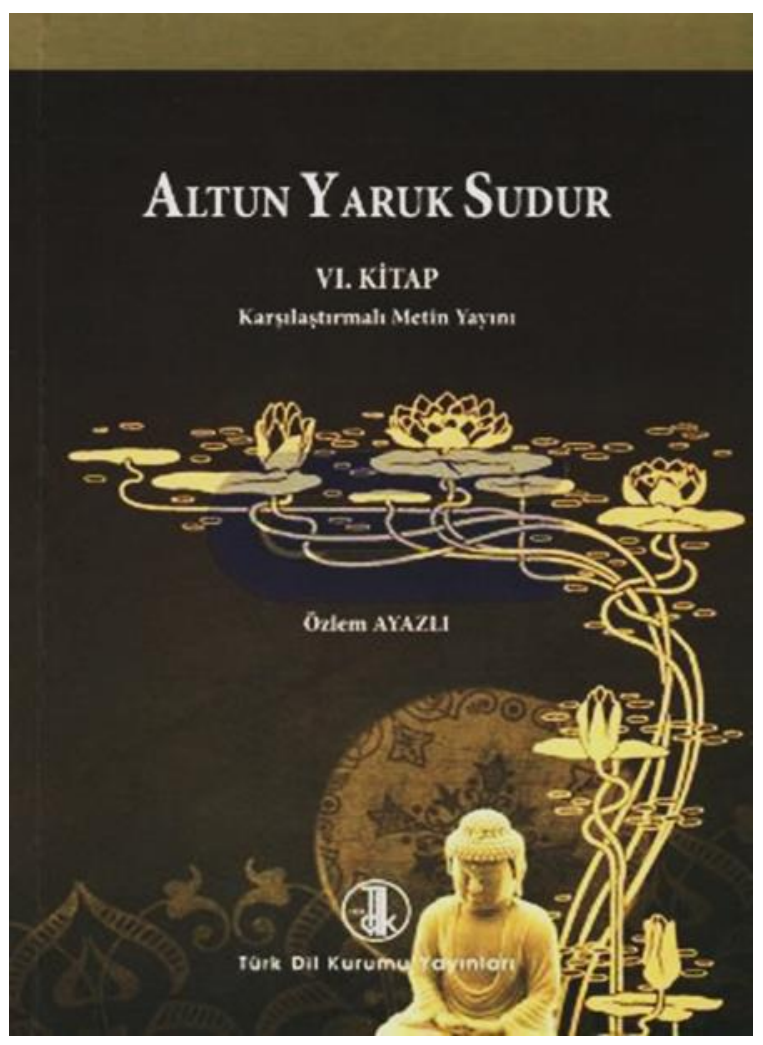

Altun Yaruk Sudur VI. Kitap (Karşılaştırmalı Metin Yayını) adlı eserin ön kapak görüntüsü

\section{3. İnceleme}

Altun Yaruk Sudur'un VI. Kitabını yani 12. bölümünü ele alan çalışmada Dr. Özlem Ayazlı, Petersburg yazmasını esas almış; ancak Berlin fragmanlarına da yer vererek

\footnotetext{
1 Sutra: Budizm'de Gautama Buddha'nın öğretilerinden oluşan ve doğrudan Buddha'nın sözlerini aktardığına inanılan metinlere verilen isimdir (Wikipedia, 2013). 
karşılaştırma yoluna gitmiştir. Adı geçen eser araştırmacının doktora tezi olup daha sonra 2012 yılında Türk Dil Kurumu tarafindan kitap olarak yayımlanmıştır.

Altun Yaruk Sudur VI. Kitap adlı eser Altun Yaruk hakkındaki genel bilgilerin verildiği Giriş, Berlin Fragmanları, Metin, Çeviri, Açıklamalar, Dizin ve Sonuç olmak üzere toplam 7 bölümden oluşmaktadır. Bu 7 bölümün sonunda fragmanların bulunduğu genel ağ (internet) adreslerinin bir listesine, tıpkıbasımlara, Radloff-Malov yayımının fotokopisine ve Nobel'in çevirisine yer verilen ekler kısmı bulunmaktadır (s. 405-506).

Giriş bölümündeki alt başlıklarda ilk olarak Uygur Edebiyatı ile ilgili genel bilgilere yer verilmiş ve Budizm tesiri ele alınmış, ardından sutralara değinilmiştir (s. 2). Budizm tesiri ile Uygur kültürü bu noktada eser merkezli bir sentez oluşturmuş hatta bu dinsel yaklaşımı daha kişiselleştirerek sanki yeni bir ekolmüş gibi ortaya koymuştur (Klimkeit, 2010: 104).

Altun Yaruk üzerine yapılan çalışmalar belirtildikten sonra araştırmanın yöntem ve tekniklerine dair bir açıklama yapılmıştır. Son olarak çalışmada karşılaşılan zorluklar, farklı fragman ve yazmalardaki çeviri ve okunma farklılıklarına değinilmiştir.

İkinci bölüm Berlin fragmanlarına ayrılmıştır. Fragmanlar " $U$ " ve "Mainz" olarak ayrı ayrı gösterilmiştir (s. 25). Bu çalışmanın ele alındığı VI. kitabın Simone Christiane Raschman tarafından hazırlanan 12. bölümüne ait 56 tane fragmanın bir listesi verilmiştir. Ayrıca bu fragman listesinin sonuna Berlin fragmanları için bir harf çevrimi eklenmiştir (s. 28). Adı geçen listeler vasıtasıyla asıl metin ve fragmanlar arasında önemli farklar tespit edilmiştir. Bu farklılıklar şu şekilde sıralanmıştır:

“... Metin ile fragmanlar arasında tespit ettiğimiz farkları şu şekilde sinuflandirabiliriz:

1. Metin ile fragmanlar arasındaki bazı harffarklllıklarl: 25. satır küzzäțü, Mainz 518 ön /1/ küzätü; 25. satır tuțsar, Mainz 518 ön /1/tutsar...

2. Metin ile fragmanlar arasında eklerde görülen değişiklikler: 25. satır şazınıg, Mainz 518 ön /3/şazının; 37. satır m(a)haraaçlara, Mainz 518 arka /4/ m(a)har(a) açlar...

3. Metinde olup fragmanda olmayan kelimeler: 31. satır ök, Mainz 518 ön /6/; 38. satır anı üçün sizlär , Mainz 518 arka /3/...

4. Metne fragmanlardan eklenmiş kelimeler, ibareler: 31. satır <ürüg uzatt > Mainz 518 ön /6/; 128. satır <inçä tep>, U 701 ön /12/... 
5. Fragmanlara göre metinden tamamlanmış eksik yerler: 834. satır işläsärlär sözcüğ̈̈ U 1638 arka /3/'e göre; 835. satır küyü küzzätü söz grubu U 1638 arka /4/'e göre..." (Ayazl1, 2012: 12).

Üçüncü bölümde Petersburg yazmasına dayanılarak oluşturulmuş esas metin verilmektedir. Bu metindeki satırların her biri numaralandırılarak gösterilmiştir. Böylece toplam metin 1331 satıra ulaşmışır (s. 63). Metnin satırları verilirken Çince karşılıkları verilerek nüsha karşılaştırılması da kolaylaştırılmıştır. Ası1 metin ile Radloff-Malov yayımının karşılaştırmaları da dipnotlar hâlinde yine bu bölümde yer almaktadır.

Ayrıca araştırmacı bu bölüm için; giriş kısmında metnin içeriğine dair kısa bir bilgi vermektedir (s. 14). Bu bölümde parçanın bir kısmının gösterilmesi uygun görülmektedir:

“... Aydınlanmaya eren dört Māhārāja Tanrılar, saṃsara içerisindeki canlıları bu döngü içerisinden çılkarmaya çalışırlar. Dört Māhārājaların bunu yapabilmesi için de sahip olması gereken şey, ü̧̈ ärdini adı verilen öğreti mücevherini gerçekleş̧tirmektir. Bu öğreti mücevheri aracıliğı ile işledikleri sevaplarla açlık, kitllk vb. gibi felaketlerin önüne geçebilir, böylelikle üç dönemdeki Budaların doğru ögretisine ulaşabilirler. Bir tür pendname kitabı olan bu Budist metinde, Budanın dört Māhārāja Tanrllara seslenişini ve ögütlerini görmekteyiz...” (Ayazlı, 2012: 14).

Dördüncü bölümde asıl metnin çevirisine yer verilmiştir. Metni Türkiye Türkçesine aktaran araştırmacı, bu sırada metinde geçen dinî terimleri Çince metin yardımı ile açıklığa kavuşturmuştur (s. 167).

Açıklamalar adlı beşinci bölümde metnin içerisinde geçen bazı kısımlar Johannes Nobel'in Almanca çevirisi de esas alınarak Uygur Türkçesi - Çince karşılaştırılması ile izah edilmiştir. Bu bölümde metnin çevirisinde olduğu gibi özel terimler ve kelime gruplarının üstünde durulmuş, Uygur Türkçesi ve Çince arasındaki farklar ortaya konulmuştur (s. 181).

Altınc1 bölümü oluşturan dizin, üçe bölünmüştür. Bunlar; ikilemeler dizini, Uygur Türkçesi - Çince dizin, Çince - Uygur Türkçesi dizini şeklindedir. İkilemeler dizininde ikilemelerin Türkiye Türkçesine aktarımı da yapılmıştır (s. 284). Çok geniş kapsamlı olan bu dizinde Altun Yaruk'a ait düzeltilmiş okuyuşlar ve farklı okuyuşlara yer verilmiştir. Bunlardan bazıları şöyledir:

$$
\begin{aligned}
& \text { “ilțürgülük } \rightarrow \text { eltingülük }
\end{aligned}
$$

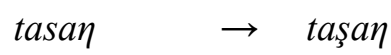

$$
\begin{aligned}
& \text { tägrilmäklig } \rightarrow \text { tägşilmäklig }
\end{aligned}
$$


tügünç $\quad \rightarrow$ yükünç...” (Ayazlı, 2012: 19).

Sonuç bölümü ile araştırma yaptığı tahlil ve tenkit için metin karşılaştırmalarının ne kadar mühim olduğunu bir kez daha vurgulamıştır. Yazar, sonuç bölümüne ilaveten yukarıda zikredilen ekler kısmıyla kitabını tamamlamıştır.

Altun Yaruk Sudur VI. Kitap adlı eserini bilim dünyasına sunarak yeni ufuklar açan Dr. Özlem Ayazlı’ya teşekkür ediyor, Türkoloji alanındaki başarılı çalışmalarının devam etmesini diliyoruz.

\section{Kaynaklar}

AYAZLI, Ö. (2012). Altun Yaruk Sudur VI. Kitap. İstanbul: TDK Yayınlar1.

ERCílASUN, A. B. (2004). Başlangıcından Yirminci Yüzyıla Türk Dili Tarihi. Ankara: Akçağ Yayınları.

J. KLIMKEIT, H. (2010). Türk Orta Asyasında Budizm. Selçuk Üniversitesi Türkiyat Araştırmaları Dergisi, 26, 93-108.

ÖLMEZ, M. (2004). Nesir. Türk Dünyası Edebiyat Tarihi. Ankara: Atatürk Kültür Merkezi Yayınları, C 4, 129-135.

SUTRA Maddesi; http://tr.wikipedia.org/wiki/Sutra, Erişim tarihi: 3 Haziran 2013. 